\title{
Learning, Doing and Teaching Together: Reflecting on our Arts Based Approach to Research, Education and Activism with and for Women Living with HIV
}

\author{
Saara Greene, Marvelous Muchenje, Jasmine Cotnam, Kristin Dunn, Peggy Frank, \\ Valerie Nicholson, Apondi J. Odhiambo, Krista Shore, Angela Kaida
}

\begin{abstract}
AвSTRACT Body Mapping has been used for thousands of years by people who want to achieve a better understanding of themselves, their bodies and the world they live in. Artist Jane Solomon and psychologist Jonathan Morgan transformed Body Mapping for the "Long Life Project", during the Médecins Sans Frontières (MSF) roll-out of antiretrovirals in Khayelitsha township, South Africa in 2001. Body mapping enables participants to tell their stories in the face of intense HIV/AIDS stigma. We adapted Body Mapping for the Women, Art and Criminalizaton of HIV Non-Disclosure (WATCH) study, a community arts based research (CBR) approach to better understand the impact that Canadian laws criminalizing HIV non-disclosure have on women living with HIV. Our national team includes women living with HIV, service providers, and researchers. This reflection illustrates our collective and iterative process of learning, teaching and doing body mapping workshops with women living with HIV in Canada. We share our experiences of coming to Body Mapping as an arts-based approach to CBR, how our roles as researchers stretched to include community-based education, advocacy, and group facilitation, and how we embodied the artist-researcher identity as we disseminate our research in ways that actively engage the general public on laws criminalizing HIV nondisclosure laws vis-à-vis Body Mapping galleries.
\end{abstract}

KeyWords Body Mapping, HIV, Women, Criminalization, Arts-based research

\section{The Criminalization of HIV Non-Disclosure in Canada}

Canada has one of the more aggressive approaches to criminalizing perceived HIV exposure in the world and is one of the only jurisdictions that classifies HIV non-disclosure as aggravated sexual assault. According to the most recent Supreme Court of Canada (SCC) ruling, people living with HIV are legally required to disclose their HIV-positive status to sexual partners before engaging in sexual activities that pose what the Court calls a "realistic possibility of transmission (R. v. Cuerrier, 1998)." Under the 2012 SCC law, avoiding the duty to disclose requires people living with HIV to have condom-protected vaginal sex with a low (i.e. $<1500$ copies/mL) HIV viral load. This overly broad criminalization of HIV non-disclosure is at odds with growing scientific consensus that people living with HIV and maintaining an 
undetectable viral load have effectively no risk of transmitting HIV to a sexual partner (Cohen et al., 2011; Rodger et al., 2016; Prevention Access Campaign, 2017).

Although the criminalization of HIV non-disclosure is often perceived as a tool to protect heterosexual women from HIV infection, a gendered analysis of the current law in Canada suggests that the law does little to protect women from HIV infection (Canadian HIV/AIDS Legal Network, 2017). HIV-related stigma and discrimination, and the complexity and risk surrounding HIV disclosure to family, friends, and sexual partners have particularly negative consequences for women living with HIV, including trans women and those facing poverty, racism, sexual violence, homophobia, ableism, the impact of colonization, and insecure immigration status (Allard, Kazatchkine, \& Symington, 2013). Under the most recent legal test articulated by the SCC, condom use (which is seldom controlled by women) and viral suppression have become critical factors in a defense to an allegation of HIV non-disclosure.

\section{Women, ART, and the Criminalization of HIV Non-Disclosure: WATCH}

Given the extremely harsh treatment of HIV non-disclosure by the Canadian Justice System (CJS), HIV-related criminalization is simultaneously embedded in and fueling HIV-related stigma and discrimination experienced by women living with HIV. The current socio-legal climate in Canada, where HIV non-disclosure prior to sex is aggressively criminalized raises important questions about stigma, discrimination and the surveillance of women living with HIV. Women who are African, Caribbean, Black and newcomers to Canada, experience the harsh blow of the criminal law as yet another form of racial oppression and sexism (Tharao, Muchenje, \& Mehes, 2013). Indigenous women are particularly affected by HIV non-disclosure requirements as approximately a third of the women who have been prosecuted for alleged non-disclosure are of Indigenous ancestry (Canadian HIV Legal Network, 2017). In response to these social and legal injustices, we engaged in a community arts-based research study exploring how the treatment of alleged non-disclosure of HIV under the CJS is understood and experienced by women and trans women living with HIV.

\section{Coming to Body Mapping}

"In Indigenous culture, when we put something down on paper we are giving it back to the paper and the paper now owns it. We don't have to carry it ourselves anymore - the paper carries it for us." (Val)

Body Mapping has been used for thousands of years by people who want to get a better understanding of themselves, their bodies and the world they live in. It was South African artist Jane Solomon and psychologist Jonathan Morgan who transformed the methodology for the "Long Life Project", during the Médecins Sans Frontières (MSF) roll-out of antiretrovirals in Khayelitsha township in 2002 (Solomon, 2007). Through the body maps, participants were able to tell their stories in the face of intense HIV/AIDS stigma and fear. Using symbols and painting, exercises, visualizations, talking in groups, sharing and reflecting, Body Mapping is a way of using art to tell life stories, while at the same time facilitating self-healing. Body Mapping can be used for research and advocacy whereby the drawings and paintings are used 
as data in themselves, supplemented by recorded reflections, or writing. Body Maps communicate feelings and experiences to raise awareness about political, personal, social, legal, and public health issues (Solomon, 2007). Ideas and issues can be explored which may be more difficult to access through verbal discussion alone and can free interviews from being intrusive (Rothe, Ozegovic, \& Carroll, 2009). Body Mapping can trigger emotional memories, yet it is also an opportunity to celebrate courage and strength (Cornwall, 1992). For the women who participated in our Body Mapping workshops, emotional memories and current day concerns as well as experiences of resilience and resistance, were represented on the body maps and through sharing circles that the women participated in at the end of each day of art making. On the last day, women also shared their reflections on their experiences of engaging in the body mapping workshops stating that it was both an emotionally challenging and healing experience, and that they would want other women in their communities to experience the body mapping process.

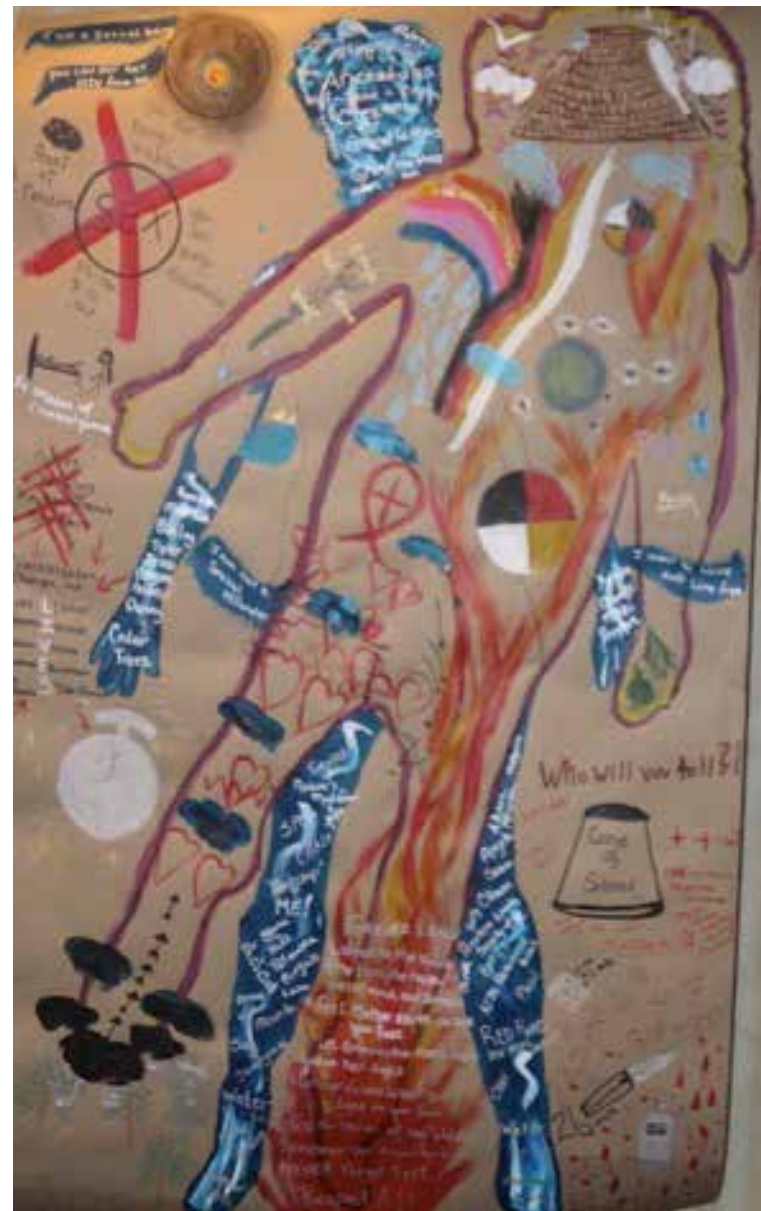

Figure 1. Valerie Nicholson's Body Map (WATCH Study, 2015) As Judith shared:

The Body Mapping approach provided a unique opportunity for the participants to connect with their inner being, reflect and introspect their lives as they engaged in art...Although the process made participants face their past and current reality in the most vulnerable way, in the end, they acknowledged how therapeutic and healing the experience was.

In the very early stages of conceptualizing how we would want to conduct our community based research study, it was unanimously agreed that an arts based approach to research would not only provide compelling data, but an opportunity for connection, support and healing for the participants. Each of us has brought a unique lens to the process. Saara, in her experience 
of conducting arts based research, witnessed the value of using arts based methods in terms of the richness of the data collected, opportunities to share stories with others in supported and supportive environments, and the potential for addressing social injustices vis-a-vis the mobilization of knowledge through art. As our team came together, Saara, Marvelous, Krista, Val and Angela brainstormed different arts based approaches to research, but it was Val who first suggested Body Mapping. Both Val and Marvelous had experienced doing their own body maps and thought that this experience would meet a core principle of our research process: to engage in research that has immediate socially just outcomes for women living with HIV during the research process itself. Early conversations with Doris Peltier, who at the time was the Aboriginal Women Leadership Coordinator at the Canadian Aboriginal AIDS Network, helped us to conceptualize our Body Mapping approach, ensuring that is was grounded in women's strengths and resilience. This approach benefited all the women who participated in the workshops including women who identified as Indigenous, Trans, African, and Caribbean, and women living with physical and visual impairments. It also benefitted us in our multiple roles as researchers and advocates as we planned and co-facilitated the workshops and, under the artistic direction of Peggy, curated our Body Mapping Gallery, which premiered in Montreal at the Canadian Association of HIV/AIDS Research (CAHR) in May, 2017.

\section{Experiencing and Facilitating Body Mapping}

I was a little apprehensive at first, because if you don't define yourself as a creative person, it is stressful. But the training brought it all together. Everyone's art work at the training was phenomenal, including mine...it created a lot of buy in for me; it actually made me a better facilitator so as to keep encouraging participants when they were passing judgment on themselves as artists. but the Body Mapping process became more important that the art itself. (Jasmine)

It is not surprising that given our diverse social positionings, particularly as it relates to HIV as a lived experience and/or as women practicing allyship to women living with HIV, that our individual and collective journey toward facilitating Body Mapping workshops have followed diverse paths. The journey to Body Mapping followed the more immediate necessity to engage in research with and for women living with HIV about their experiences of living in a socio-legal context in Canada where HIV is criminalized. This included the palpable fear surrounding reports of people living with HIV being charged for not disclosing their HIV status, what this meant for women in the context of engaging in sexual relationships, and how this fear seeps into other areas of their lives. The desire to approach this research through Body Mapping followed. As Angela shared:

The richness of Body Mapping seemed like a necessary counterpoint to the crudeness and inhumanity of the law, which wants to view women living with HIV as suddenly 
unaffected by gender and power inequities, violence, lower legal status, and other social injustices...As a researcher practicing allyship to women living with HIV, the experience of facilitating Body Mapping was deeply humbling and a privilege.

Importantly, we recognized the potential that Body Mapping offered for knowledge generation, community connection, safety, and healing, yet we collectively agreed that we had an ethical responsibility to know, through experience, what we were asking of women before we endeavored to use Body Mapping as a research method. As Kristin reflected:

We were brought to understand ourselves in entirely unexpected ways, in a setting which engendered the building of trust, intimacy, and bonding. In this way, we came to understand the scope of the methodology's impact, so that we were in turn equipped not only with a skillset but with an embedded knowledge of and respect for its power. It's clear to me why we had first to experience the Body Mapping as participants before we could be qualified to co-facilitate these workshops.

A critical learning for many of us, was the importance of grounding ourselves culturally and spiritually before, during and after the workshops. Out of respect for the Indigenous territories where our research was to take place and of our Indigenous team members and participants, we chose to ground our Body Mapping training in Indigenous teachings and ceremony. Our training was supported by an Elder who connected her local teachings to our collective and individual experiences. This process was powerful for all of us, regardless of our own traditions. As Judith remarked:

Personally, I became more aware of the role of culture and beliefs in our lives. It was interesting to note how deeply embedded culture is in our histories and how culture transcends geographies. As a black African woman, I did not realize how similar my culture and beliefs were to those of the indigenous community. Through the sharing circles, I immersed myself in the healing process that was facilitated by an Indigenous elder. This was a grounding process that helped me as a facilitator to connect with the process as well as with the participants who embodied different identities and cultures.

Of critical importance to our reflecting on the facilitator experience, was the recognition that some of us also held multiple identities and roles in the community. As Marvelous shared, this was both a challenging and gratifying experience that shaped her entire experience:

As a woman living with HIV, service provider and researcher it was hard to balance my roles, and maintain the boundaries...I had to constantly remind myself that whatever they were sharing that day, I did not have to compare it with what I knew about them already. I respected their experiences, and got to learn more about their struggles and resilience. This experience brought us closer together. Their thoughts resonated 


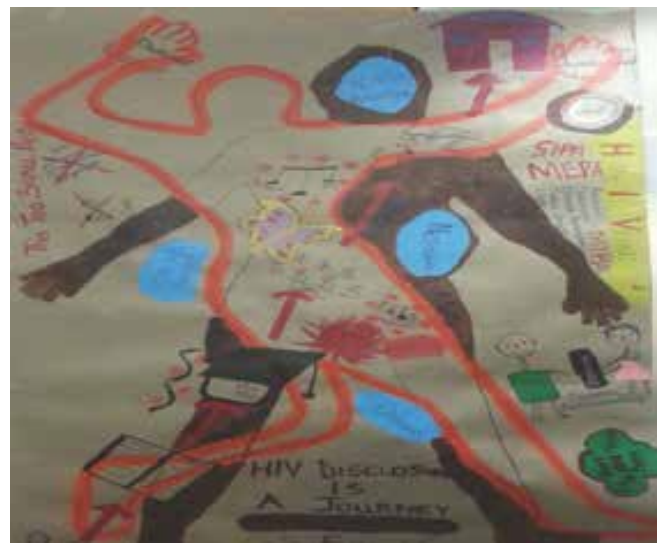

Figure 2. Marvelous Muchenje Body Map (WATCH Study, 2015) with my thoughts - I felt their pain, I cried when they cried, and laughed to the jokes we shared.

\section{"United We Stand, Divided We Fall": Doing Research as Advocacy}

\begin{abstract}
And those days we spent together - it created a safe space, but also gave us the connection to others, and to reinforce that message: that you aren't alone in this. The ultimate goal is to take this research and educate those who need to be taught...(Val)
\end{abstract}

Embodying the researcher/educator/advocate role was powerful and necessary. As Marvelous stated, "Racism, gender based violence, discrimination and human rights. Being together ignited our passion, confirmed our resilience, and made us realize that united we stand, divided we fall."

We therefore recognized the potential that moving through the Body Mapping process had for using art as a way to document strategies of resilience, resistance and social change. As Judith explained, "The body maps helped women connect their bodies to the social relations of HIV criminalization... furthermore, using the body maps, the women outlined their coping and resistance strategies."

At the same time, the Body Maps illuminated the confusion and unanswered questions the women had about the law. As facilitators, we were regarded as experts by the women and this triggered our collective moral and ethical compass and commitment to social change; consequently, this propelled us to include a criminalization of HIV non-disclosure education session as part of the workshop. The sessions ensured that the participants had the correct knowledge of the law and their legal rights, and answers to their questions in 'real time'. This work has continued long after the workshops have ended. Kristin reflected:

Once we were conducting the research, it became clear that our roles were multifaceted. As fears and misinformation emerged we were in an excellent position to dispel myths, clarify points of law, and offer reassurances...In the weeks and months following our workshop, participants reached out frequently to access support, guidance, and to network with other participants, having found a place in a community where they could speak openly and be heard.

\section{Embodying the Researcher Artist Identity in Action}

The community of women living with HIV was traumatized when charges were laid 
against their peers. I wanted to advocate for change, but didn't know how. Body Mapping has been the best tool for a woman who has a passion for public art. (Peggy)

Most of us would not have called ourselves 'artists' before engaging in our Body Mapping workshops. Most of us would not claim to be artists even now. However, as Peggy voiced above, we have all experienced and witnessed the power of art, even the comfort of art, in asking and responding to difficult questions. We have learned together that doing art helps us and the women we care about to convey the whole range of complicated, painful, and empowering experiences that women living with HIV have as they bump up against criminalizing and stigmatizing environments. Our hope was that through creating a gallery of the women's body maps at the end of each workshop, we could create an alternative environment. An environment where truths were told in ways that that illuminate resilience, resistance, and action.

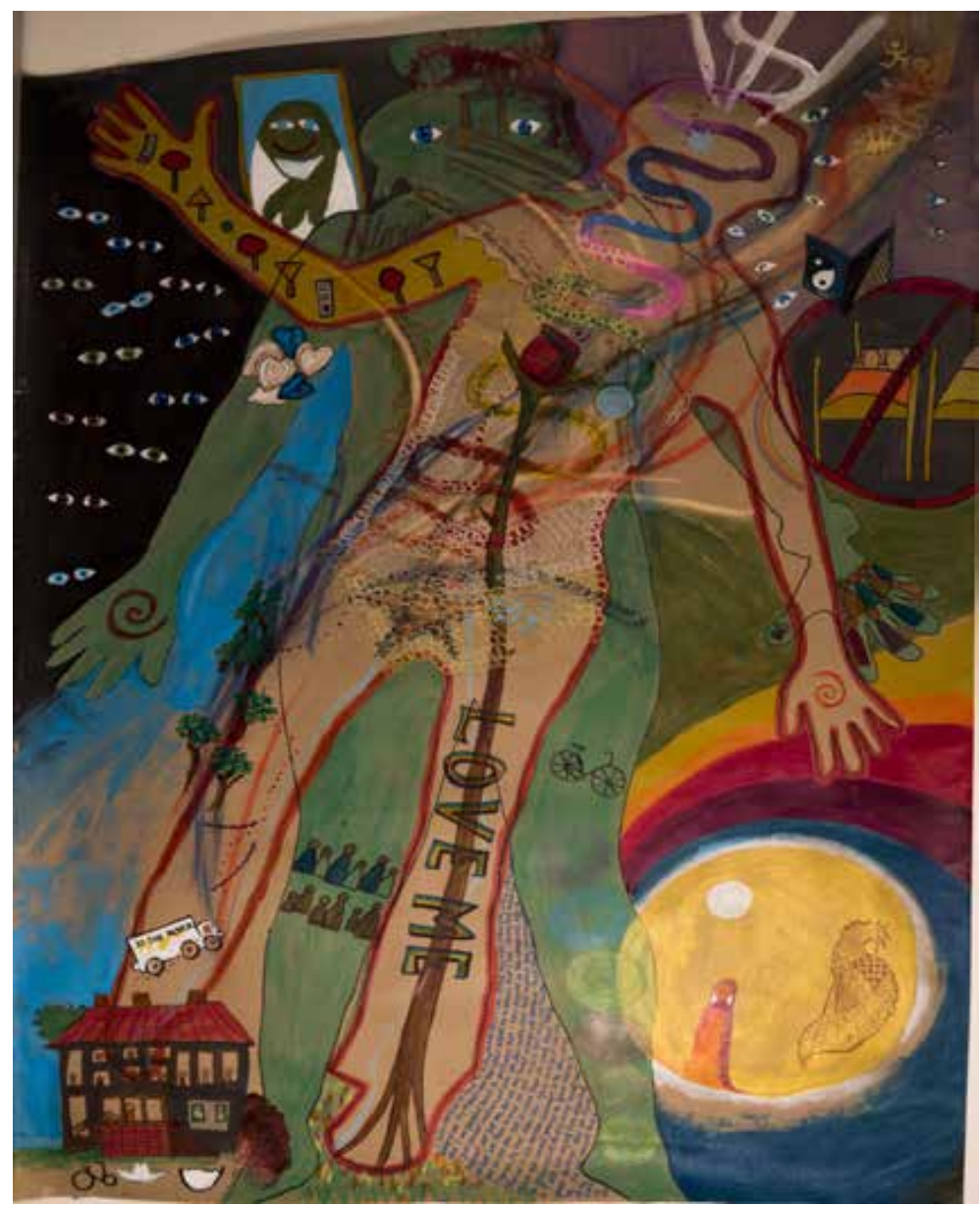

Figure 3. Peggy Frank’s Body Map (WATCH Study, 2015) 
As we have endeavored to share our research in ways that enable us to embody our researcher, educator and advocate identities, we have participated in dissemination and knowledge mobilization activities that engage the general public on issues of criminalization vis-à-vis public Body Mapping galleries. Many participants in the research were willing and excited to use their maps for public awareness. Peggy, had the initial idea for the CAHR Gallery. Her artistic vision came from imagining how close she was to being imprisoned by a vindictive partner. We agreed with her that the women's Body Maps needed to be hung in a safe place, but also one that reflected entering another world: prison. By hanging strings from the ceiling, spaced like prison bars, the women were encased in a thoughtful venue for conference participants to reflect on the impact of the law.

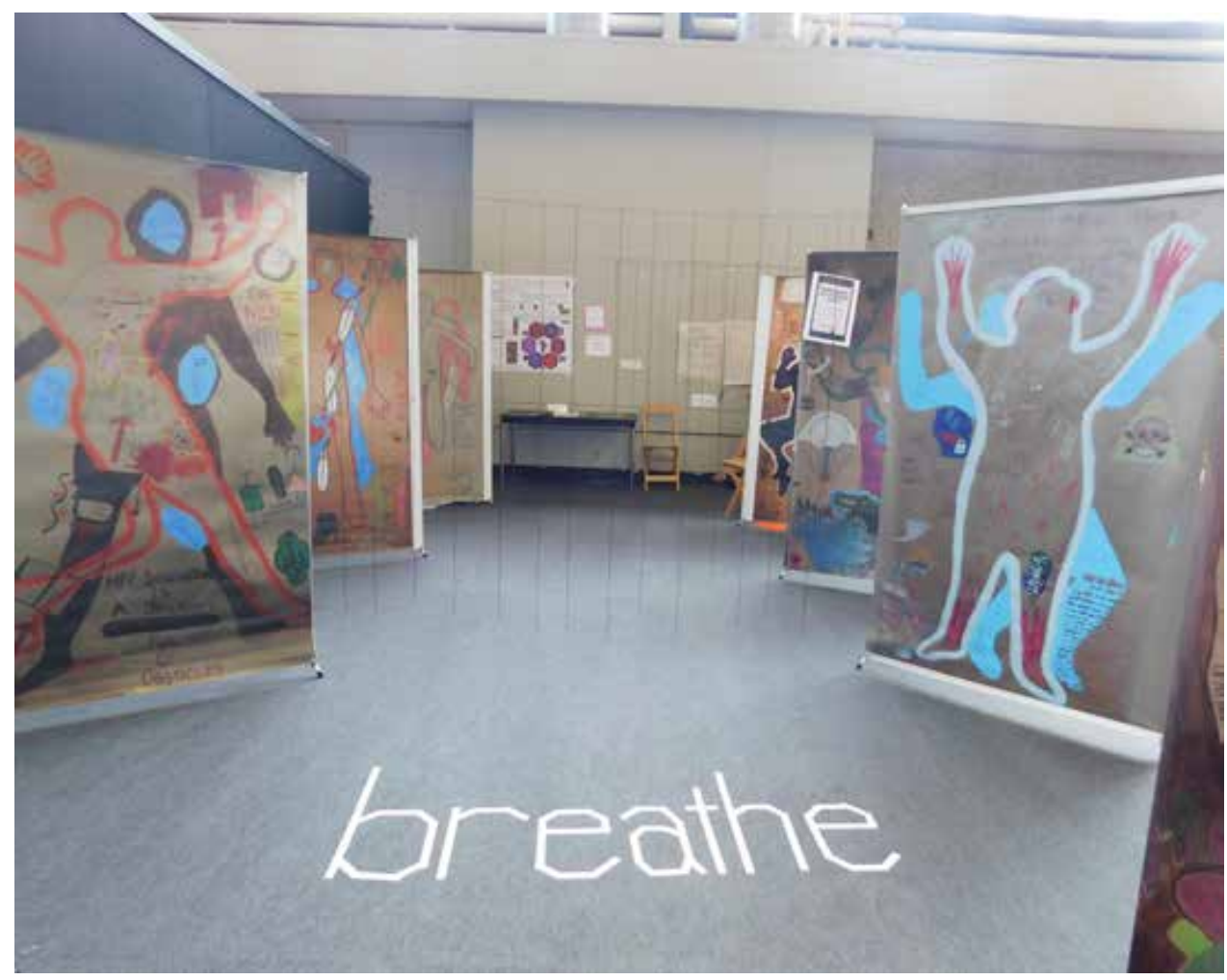

Figure 4. WATCH Study Body Map Gallery, IAS, Amsterdam, 2018

This was a powerful experience for us all:

It was an honour to witness the attendees at CAHR move through the Art Gallery. It comes back to my Indigenous cultural background. If I am tasked with being a witness to someone's story, it is my duty to lead others through the story and hold it. To have that honour of being able to be a guide at the Gallery when people ask questions of 'What does it mean?'; we carry the words of the women. (Val) 
And, as Kristin added:

It was moving and encouraging to hear compassionate responses, to witness moments when people were brought to tears, or to outrage. Equally, it was encouraging to hear people remark on the resilience and beauty they found in the Body Maps and in the lives of the women.

What is perhaps more striking, is the way the women embodied the artists in themselves. As Jasmine witnessed, "I know women who have them up in their homes. It says that the experience was way more than the research; that they connected it to their lives - there is pain and there is beauty and they want to share it..."

To date, the Body Maps, accompanied by participant narratives, have been displayed at regional, provincial, and national conferences. At the time of writing, we have just submitted an application to host our Body Mapping Gallery at the International AIDS Conference in Amsterdam as a way to engage people living with HIV, activists, researchers, legal advocates and others in a global effort for Canadian legal reform.

\section{Not Quite the Conclusion}

Our work together is not complete. We have a long way to go in our commitments to end HIV stigma and to advocate for legal reform on behalf of women living with HIV in Canada and around the world. However, we conclude our 'report from the field' in a way that honours our voices and experiences as arts based researchers who are committed to learning, doing and teaching together. With that, we end with Jasmine who so beautifully stated:

Personally, I feel like I'm actually part of something huge and important. I got to show my body map to my daughter and we got to talk about what it was, and what it meant. There are so many ways to unpack something and some are more painful than others. Body Mapping is a gentle way to look at uncomfortable topics.

\section{About the Authors}

Jasmine Cotnam resides in Northwestern Ontario and holds the positions of National APHA Liaison and Research Coordinator at the Canadian Aboriginal AIDS Network. Jasmine is an Indigenous woman and mother who has has been publicly open about her HIV status since her diagnosis less than a decade ago. 
Kristin Dunn has moved from in-hospital advocacy to work as a Peer Educator with the Elizabeth Fry Society of SK, offering prison in-reach and a support group for women living with HIV. She's on the Patient and Family Advisory Council for HIV (Waniska PFAC) and works with the Northern Intertribal Health Authority

Peggy Frank is a trained biologist, but worked in the arts, policy, and sciences. She co-founded the Southern Gulf Islands (HIV) Support Society and positively AFRICA. With a brush, pen or a meditation in hand, she has taught Body-Mapping and Therapeutic Touch extensively throughout Canada and Sub-Saharan Africa.

Saara Greene (corresponding author) is an Associate Professor, School of Social Work, McMaster University and mother of two. She is passionate about engaging in community arts based research and arts driven knowledge mobilization activities with women living with HIV. She cares deeply about doing and using research for advocacy, education and social change. Email: greenes@mcmaster.ca

Angela Kaida is an epidemiologist and Canada Research Chair at Simon Fraser University whose global research program centers on a rights-based, evidence-informed, and communitydriven approach to sexual and reproductive health among women and youth affected by HIV.

Marvelous Muchenje is the Community Health Coordinator at Women's Health in Women's Hands, Community Health Centre, Toronto. She has seventeen years' experience working in the non-profit and NGO sector, with ten years specializing in outreach to ethnic-cultural communities. Diagnosed with HIV in 1995, she continues to participate passionately in the HIV movement.

Valerie Nicholson is A Spirited Indigenous Warrior Woman, and became active in HIV/AIDS advocacy in 2008. She was the first Indigenous women to Chair the Board of Positive Living B.C, and is currently an Indigenous Peer Navigator, and Chair of the Canadian Aboriginal AIDS Network.

Apondi J. Odhiambo is a PhD candidate at University of Toronto, Dalla Lana School of Public Health and CIHR Doctoral Research Scholar. Her research is on how intersections of public health, criminal justice, and immigration systems impact criminalization laws and HIV prevention and healthcare engagement among Black immigrants and refugees in Canada.

Krista Shore is a mother of four from Peepeekisis First Nation. Involved in the HIV movement since diagnosis in 2007, she founded Circle of Courage, a holistic approach to health and well being for women with HIV. Krista received 'Igniting the way Forward Women's Award' for courage and leadership in Saskatchewan, 2017. 


\section{References}

Allard, P., Kazatchkine, C., \& Symington, A. (2013). Criminal prosecutions for HIV non disclosure: Protecting women from infection or threatening prevention efforts? In J. Gahagan (Ed.), Women and HIV Prevention in Canada: Implications for Research, Policy and Practice (pp. 195-218). Toronto, ON: Canadian Scholars' Press.

Canadian HIV/AIDS Legal Network. (2017). Women and HIV: The criminalization of HIV nondisclosure. Retrieved from http://www.aidslaw.ca/site/women-and-hiv-women-and-thecriminalization-of-hiv-non-disclosure/?lang=en

Cohen, M. S., Chen, Y. Q., McCauley, M., Gamble, T., Hosseinipour, M. C., Kumarasamy, N., .. . Pilotto, J. H. (2011). Prevention of HIV-1 infection with early antiretroviral therapy. New England Journal of Medicine, 365(6), 493-505.

Cornwall, A. (1992). Body mapping in health RRA/PRA. RRA Notes, 16, 69-76.

Prevention Access Campaign. (2017). Undetectable=Untransmittable. Retrieved from https://www. preventionaccess.org/undetectable

Rodger, A., Cambiano, V., Bruun, T., Vernazza, P., Collins, S., van Lunzen, J., . . Beloukas, A. (2016). Sexual activity without condoms and risk of HIV transmission in serodifferent couples when the HIV-positive partner is using suppressive antiretroviral therapy. Journal of the American Medical Association (JAMA), 316(2), 171-181.

Rothe, J.P., Ozegovic, D., \& Carroll, L. J. (2009). Innovation in qualitative interviews: "Sharing Circles" in a First Nations community. Injury Prevention, 15(5), 334-340.

R. v. Cuerrier, 25738 S.C.R. 371 (1998).

Solomon, J. (2007). Living with X: A body mapping journey in the time of HIV and AIDS, facilitator's guide. Johannesburg: REPPSI.

Tharao, W., Muchenje, M., \& Mehes, M. (2013). An evidence-based intervention to support African, Caribbean, and Black women in Canada to disclose their HIV-positive status. In J. Gahagan (Ed.), Women and HIV Prevention in Canada: Implications for Research, Policy and Practice (pp. 105-134). Toronto, ON: Canadian Scholars' Press. 